\title{
The puzzle of language learning: From child's play to 'linguaphobia'
}

\author{
Alison Wray Cardiff University, UK \\ wraya@cf.ac.uk
}

A new education policy for England, announced in Spring 2007, aims to introduce the learning of a foreign language to all children from the age of 8 by the year 2010. But there was a similar initiative in the 1960s and it didn't work then, so why should it now? This presentation explores the reasons underlying the belief that children can 'naturally' learn another language if they begin young enough, and considers reasons why classroom learning may not always tap into whatever natural language learning skills children have. Drawing on a range of previously published research and my own recent empirical studies, I suggest that, unless we are careful, our primary-age children will be flung into an adult-style learning approach, which they are too immature to handle. How, then, can young children's learning potential be exploited most effectively? The role of multiword sequences as a form of lexis is considered, making reference to my model of formulaic language processing e.g. Wray 2002. Consideration is given to how memorising useful wordstrings may assist children in developing a view of language knowledge that promotes effective learning.

\section{Introduction}

In the Spring of 2007, Lord Ron Dearing published a report commissioned by the United Kingdom government (DES 2007), regarding the teaching of foreign languages in schools in England. ${ }^{1}$ It confirmed recommendations previously made in the 2002 National Languages Strategy 'Languages for All, Languages for Life' that, by 2010, all primary-age children should have the opportunity to learn at least one foreign language in school. This new policy in England may affect current practices elsewhere in the UK, though in fact in Scotland foreign languages have been taught in primary schools - albeit not from age 8 - for some years (Action Group for Languages 2000: section 5) . Similarly, in Wales all primary school children are already taught another language, since both Welsh and English are part of the

\footnotetext{
${ }^{1}$ The four constituent countries and principalities of the United Kingdom - England, Scotland, Wales and Northern Ireland - have measures of devolved authority in relation to education policy. The Dearing report relates to England, but is likely to act as a major reference point for decisions made in Wales, Scotland and Northern Ireland.
}

Revised version of a plenary paper presented to a multidisciplinary audience of researchers in the natural sciences, social and behavioural sciences and humanities as part of the Vice Chancellor's Lecture Series 2006/7, Cardiff University, 31 January 2007. 
curriculum. In the spirit of the Dearing report, though, a major study is underway as part of Wales' 'Languages Count' strategy, to follow and support 105 primary schools where an extra foreign language - usually French, but in some cases German, Spanish or Italian - is being taught at Key Stage 2 (CILTCymru 2006). 2,3 The project also works with 22 of the secondary schools into which these primary schools feed, to assess their capacity to provide an effective transition that develops the children's previous learning.

Well, what's so special about all of this? Surely it's a good thing for English-speaking children to be exposed to foreign languages at a young age. After all, many countries worldwide introduce English as a foreign language before the age of 10, and it must be in the interests of the UK's economy and cultural standing that we also learn the languages of other nations. A priority identified by the European Union is that 'every European citizen should have meaningful communicative competence in at least two languages in addition to his or her mother tongue' (Commission of the European Communities 2003: 4), and most member states are well ahead of the UK in achieving that goal.

English is, of course, unusual - one might venture to say 'special' - for it occupies a unique place in worldwide culture and commerce. Much has been said and written about the extent to which this fact explains the extraordinary enthusiasm and success of so many learners of English as a foreign language, compared with the less impressive achievements that native English speakers have with other languages. The standing of English worldwide could be viewed as a justification for complacency in relation to the learning of other languages. Yet the ELT industry suggests we could do a good job. There is considerable research and experience into how to teach English as a foreign language, and it should be relatively straightforward, one would imagine, to translate the best ideas from that context to British foreign language classrooms.

However, the new policy resonates awkwardly with an unfortunate venture some 40 years ago. In the 1960s there was a major - and very popular - British government initiative to teach French in primary schools from the age of 8 . Although it was just a pilot scheme, a vast number of schools nationwide joined in, and it showed every sign of being hugely successful. But when in 1974 the official report on the outcomes of the pilot was published by Burstall, Jamieson, Cohen \& Hargreaves (see Burstall et al. 1974), it was so scathing that it effectively put paid to the entire initiative. There were several reasons for Burstall et al.'s concerns, but two are particularly relevant to my theme today.

Firstly, in answer to the question 'Is any substantial gain in mastery achieved by beginning to learn French at the age of 8?' the Burstall report stated: 'This question can be answered unequivocally in the negative' (Burstall et al. 1974: 243). Secondly, the report claimed that some children were actually being PUT OFF learning languages by their experience of this early exposure (ibid.). Of course, this is far from what most people had expected. There were

\footnotetext{
${ }^{2}$ Key Stage (KS) One: School years 1 and 2, ages 5-7 years; KS Two: years 3-6, ages 7-11; KS Three: years 7-9, ages 11-14; KS Four: years 10-11, ages 14-16.

${ }^{3}$ Wales offers useful future opportunities for comparisons with major studies in other countries, such as the Barcelona Age Factor (BAF) study in Spain (Muñoz 2006c). The subjects in the BAF study were bilingual in Catalan, the community language, and Spanish, the national language, by the time they began learning English at age 8 (Muñoz 2006b: 13f.). In contrast, English-speaking children in Welsh-medium education undergo immersion in the community language not the national one, making the Welsh experience a useful supplement to the Catalan one.
} 
good reasons to suppose that children would take language learning in their stride, and do it better than adults. But Burstall et al.'s findings suggested very much the contrary. Although the children did learn, and some promising abilities were noted, by the age of 16 they were no further ahead than children who began to learn at age 11 (ibid.). ${ }^{4}$ As a consequence of the Burstall report, foreign language provision was largely withdrawn from primary schools, and the previous norm was reinstated: children gained their first exposure to a foreign language when they entered secondary school aged 11 to 12 .

In the light of the outcomes of the 1960s experiment, it seems reasonable to ask whether the problems encountered then can be avoided this time round. One would certainly hope that some lessons have been learned. The single biggest problem in the 1960s was that only French was introduced, and it was difficult to find enough teachers with the necessary skills to service a level of demand that was quickly out of control. This time, ANY language can be taught. However, that brings its own difficulties. The intention is that children can continue learning in their secondary school the language they began in their primary school, but that could require each secondary school to provide tuition in several languages.

All the same, teaching whichever language is available and most suits the local environment is an imaginative proposal, not least because there are many areas of the UK in which children would benefit from the opportunity to learn more of, and about, the language that they speak at home. However, ethnically mixed areas present the challenge of deciding which minority language(s) to teach. Might there be equality issues in relation to offering some children tuition in their home language and not others? And is it reasonable to teach, say, just Urdu when a class contains L1 speakers of Urdu, Somali and Polish?

However, my talk is not about the practicalities of provision, nor the potential political and social issues arising from the policy. Rather, I want to focus on the AGE question, and specifically whether 8 is a good starting age for foreign language learning in school. There are beliefs and assumptions about how children learn languages, compared with how teenagers and adults do it. Ultimately, it must be by understanding whether these beliefs and assumptions are right that predictions can be made about whether teaching a foreign language to 8-year-olds will work in the UK. A key question, therefore, is just what happens to language learning as we get older.

\section{Is there a 'critical period' for language learning?}

The notion of a critical period for language acquisition was first proposed in the late 1950s by Wilder Penfield (Penfield \& Roberts 1959: 236, 255) and subsequently, and perhaps more famously, by Eric Lenneberg (1967). This was a BIOLOGICALLY critical period, based on plasticity in the brain during the early years. By puberty, if not sooner (De Keyser 2000: 518), the brain's wiring was understood to be more 'set', so that new learning mapped onto existing structures (for recent overviews of evidence for and against the critical period hypothesis, see Singleton 2005; Nikolov \& Djigunovic 2006; Muñoz 2006b).

\footnotetext{
${ }^{4}$ Since then, other studies have confirmed their basic findings (e.g. Cenoz 2002; Muñoz 2006c).
} 
In a very well-known development of the critical period position, Stephen Krashen, in the 1970s and 1980s, proposed that languages can be ACQUIRED implicitly or LEARNED explicitly (e.g. Krashen 1985). While acquisition entailed a natural assimilation of linguistic knowledge through usage, learning was an intellectual pursuit, based on explicit attention to the language forms. Although he hypothesised that acquisition was possible for adults, if they were introduced to the language in an appropriate way, he supposed that there was nevertheless a strong tendency for adults in the classroom to miss out on the opportunities and advantages of acquisition and to operate as learners rather than acquirers.

Much water has flowed under the bridge since then, and huge quantities of research have been carried out into the reasons why some individuals end up with better foreign language skills than others. A major variable is recognised to be individual differences in motivation and aptitude (see, for instance, papers in Robinson 2002), though adequate predictive models, that might assist the learner in working to his or her strengths, remain somewhat elusive. A tempting inference in relation to individual learner differences is that - since they relate somewhat to aptitudes for explicit learning - they apply only after childhood. If so, exposure to another language below the 'critical age' should result in uniformly very good outcomes. However, I'll suggest later that the devil is in the detail here: or, specifically, in what the word 'exposure' is taken to mean.

It has often been observed that the differences between a child learner and an older learner need not be solely - and perhaps not even primarily - to do with what the brain can handle so much as the profound differences in how children and adults engage with the world. The way in which a young child experiences exposure to a new language is qualitatively different from anything an older learner could expect or easily engineer. A preschool child does not choose to study another language because it would be interesting to do so, or would give her academic credits. Rather, the child approaches the language in an entirely functional way: it is an encoding of necessary communication. The child's priority is not to learn the language but to command her environment through communication. Even an adult totally immersed in a new language environment is not in quite that situation, because rationality, mature knowledge of another language, and a raft of adult needs and responsibilities create a different learning context.

The functional drive to learn can be seen in detailed longitudinal studies of second language acquisition in young children. In one study, a Japanese-speaking boy called Takahiro was observed between the ages of $2 \frac{1}{2}$ and 3 years old, as he was exposed to English as a second language in nursery school (Itoh \& Hatch 1978). The researchers found that he largely failed to engage with English for as long as his mother was present, for she acted as an agent for him to meet his needs through the medium of Japanese, his L1. When she withdrew, so that the boy was obliged to use English if he wanted to manipulate his environment, he very quickly acquired it.

The child's experience of the world is so different from the adult's that the unquestionable age-related effect on language learning cannot be as easily attributed to solely biological differences as the original critical age theorists supposed (Singleton 2001: 85f.). Working out the respective roles of biological maturation and of contextual, psychological and social variables in determining the success of language learning is of some importance for researchers and practitioners, because while biological differences may be relatively intractable, there 
is always the possibility that the other factors could be manipulated in order to improve outcomes.

One reason for supposing that such variation may exist is that, despite frequent claims to the contrary, the achievement of fully native-like proficiency is NOT beyond the scope of adult learners. Some - albeit only a minority - do seem to 'crack the code' sufficiently to operate with the same level of proficiency and accuracy as native speakers, give or take a slight accent. Researchers, of course, are interested in how they achieve this. Have they managed to replicate the processes by which children learn languages? Or have they achieved the same EFFECT, but built upon a quite different knowledge base and processing style?

I am one of a number of linguists who investigate aspects of how language learning and processing is done. In my recent research I have been looking at types of what we might call extreme learning, where something unusual about the needs of the learner or about the language she is exposed to helps us to get a glimpse at things that are normally rather difficult to see. But I'll come to my own studies later. First of all we need to explore some of the context for studies like mine.

\section{Perceptions of language}

We can begin with the question of whether adults and children have a different perception of what language learning IS. In 2000, a study was conducted on behalf of the European Commission's Education and Culture Directorate-General, to discover the language knowledge and attitudes to language learning of citizens in 15 European countries. I want to pull out responses to just two related prompts. Sixty-five per cent of respondents agreed with the statement 'Learning an additional language would be too difficult for me', and 64\% agreed that 'Learning an additional language would be too time-consuming for me' (INRA 2001). ${ }^{5}$ In other words, the people interviewed tended to see languages not just as difficult to learn, but as TOO difficult. We can imagine them standing outside this THING - this foreign language - and looking into it with some measure of disappointment or frustration. Mastery of it was something they felt effectively excluded from.

Of course they had a point: languages are complicated and take time to learn. They're full of traps for the unwary. You no sooner get accustomed to a pattern than you find there are sub-patterns and exceptions. Languages are like that, and this has some bearing on our story, as I'll explain later. If you learn a language in a classroom, you have to address this issue of complexity at some point, even if your teacher takes a rather 'communicative' approach that lulls you into a temporary false sense of security. At some point the textbooks start getting serious, and you need to learn the words and the patterns.

But babies and young children manage to learn language without textbooks, of course. So how do THEY perceive language learning? The problem with the very youngest children is that they can't articulate their perceptions of language. So it's useful to ask slightly older children, who can. Let's consider the experiences of one particular child, whom we'll call Katie. Katie is 10 years old. Until she was 8 and a bit, she attended a primary school in the United Kingdom. She didn't study any foreign languages there. Then her family moved to

\footnotetext{
${ }^{5}$ Statement 1: Disagree 24\%, Don't know $11 \%$. Statement 2: Disagree 25\%, Don't know $11 \%$.
} 
Australia. Katie joined a primary school class that had been studying a foreign language for several months. It was Japanese.

About three months after Katie joined her class, I asked her about her experiences of learning Japanese. 'It's terrible!' she said. 'Oh?' I asked, 'What's so bad about it?' 'Well' she said, 'for instance: the teacher shows us a film in Japanese. Then afterwards she asks us what it was about. But we don't know! Because it was in JAPANESE!' Katie's exasperation tells us something about how she perceived language learning at that time. From her point of view, a language was not something that you LEARNED but something that you KNEW. And if you didn't know it, it was really quite unreasonable to be expected to understand a film in it. This rather all-or-nothing perspective might seem, at first glance, to be the very last thing that would help a child learn a language. But in fact it seems to be the reason why children are actually very well placed to develop native-like skills.

\section{Children's learning: Nora}

To see this all-or-nothing approach in action, we need to look at detailed studies of how even younger children acquire a second language, when they are essentially dumped - or 'immersed' as we like to call it in technical terminology - in the new language environment, to sink or swim. With children of up to around 5 and 6 , you really seem to get a chance to see a version of the natural language acquisition that babies engage in. The great thing about their being a little bit older is that it's easier to figure out what they are doing.

I'd like to use the example of Nora, a 5-year-old child studied by Lily Wong Fillmore in the 1970s. It's an old study, but it's still very useful to us, because it was hugely detailed; and it represents a pivotal point in research into how children learn a second language. Nora was a native speaker of Spanish, living in California. Her English input came entirely from attending kindergarten and playing with children she met there, and Wong Fillmore observed her and four other children over a nine month period (Wong Fillmore 1976, 1979). Nora turned out to have what Wong Fillmore describes as 'spectacular success as a language learner' (1979: 221). In fact, she went, in 9 months, from having no English at all to sounding like a native. So what sorts of things characterised Nora's approach?

Firstly, she seemed not to have major inhibitions about using new material the moment she learnt it. So she was out there using words and expressions straightaway. Secondly, she liked make-believe games that entailed a large quantity and range of language, such as playing 'house', 'schools' or 'doctors' (1976: 132). Thirdly, she spoke up for herself: she was a strong character with strong ideas. Wong Fillmore says she was 'constantly embroiled in one controversy after another, all of which required a great deal of verbal activity' (1979: 223). Hand in hand with this sometimes confrontational approach, she was, fourthly, very sociable, with lots of English-speaking friends. Indeed, she preferred the company of children over that of adults - and it is known that children's talk is more rooted in concrete, tangible things than adults' talk is, so it makes language learning easier. Fifthly, she was impulsive, so that when she wanted to say something, she said it. She wasn't going to wait till a Spanish speaker was there for her to talk to, so she just had to say it in English. And finally, her principal goal was not to learn English, but to establish social relationships with a group of children who 
happened to speak English (1979: 208): 'she not only wanted to be around English speakers, she wanted to be LIKE them, and, therefore, she adopted their way of talking' (1979: 227). This particular combination of personal character traits seems to have provided Nora with an excellent basis for learning English.

There was one specific thing that she did, though, that I want to explore in a little more depth. It was a rather bizarre strategy, but clearly effective. Nora tended to notice some sequence of words, and then use it on every possible occasion, even if she wasn't entirely sure what it meant. The result was that she came across as if she knew more than she actually did. By using memorised formulaic expressions such as like dese and right here, she sounded native-like and idiomatic, before she had a full capability to compose original language. She adopted in the high school, which Wong Fillmore describes as "just a nice phrase which she sometimes appended to her sentences. It sometimes meant "in class"; at other times, it meant nothing in particular' (1976: 494). A similar example came from Ana, the next youngest subject in the study. She used when I come home, which she added to her utterances with no apparent meaning (1976: 446).

Now it must be said that this is probably a kind of practice that only little children could get away with. Wong Fillmore says that people found it rather sweet and charming. If you were an adult learner, people would look at you rather strangely if you started putting random phrases on the end of your sentences. And that fact reminds us that critical periods for effective learning can be created not just by biological changes, such as neurological plasticity, but also by social changes - what you can get away with and, more generally, what you need to achieve with language and what the consequences are of not achieving it. The willingness of Nora and Ana to memorise and use strings before really understanding them seems to be a significant strategy of children bootstrapping themselves into a language. In contrast, adults seem to resist such memorisation - otherwise learning a phrasebook would be the preferred route to fluency.

So, Nora had everything going for her, and she acquired English at a tremendous rate. She was 5 . How much older would she have needed to be for things to be less easy? Wong Fillmore studied four other children too. The oldest was only 8 years old by the end of the study, so they were all pretty young, but she could already see certain features in the approach of the older ones that were getting in the way of their learning. They seemed more inhibited, more concerned about 'getting it right' and often would not speak till they knew they had the right words and grammar. This matches De Keyser's (2005) observation that 'somewhere between early childhood and puberty children gradually lose the ability to learn a language successfully through implicit mechanisms only' (sect.5). There seems to slowly develop in children greater awareness of language as a phenomenon in its own right, as opposed to just a tool for communication; that is, as they start to adopt a more 'intellectual' approach to language learning. Muñoz (2006b: 33) concurs: 'The older learners' superior cognitive development enables them to take greater advantage of explicit teaching processes in the classroom'. ${ }^{6}$

\footnotetext{
${ }^{6}$ However, Martin (2000: 66f.) urges caution in interpreting studies where, often for reasons of tight research design, younger and older learners are taught and tested in the same way, for approaches appropriate to the older learners will often disadvantage the younger.
} 
Where, then, does the typical foreign language learning experience of British schoolchildren fit in, whether they're aged 8 or 12? The most major difference from children like Nora, of course, is that, instead of immersion, they will have just an hour or two a week of class lessons (compare Muñoz 2006a: vii). Where Nora was surrounded by native speakers as her models, in a classroom there are lots of learners and only one model ... nor will that model always, alas, be a particularly proficient one. Where Nora surrounded herself with a social group who shared the work of enabling her to communicate with them and supported her learning, in the school classroom the learner's social identity is linked to a group of people who DON'T know the language, and maybe don't much value learning it. These differences must profoundly affect the outcomes. So let's turn to a classroom situation, to see just what happens there. The study I want to use was done in the late 1990s by researchers at Southampton University. ${ }^{7}$

\section{Secondary school learners of French}

The Southampton team studied how French was learned in the English secondary school context (Mitchell \& Martin 1997; Myles, Hooper \& Mitchell 1998; Myles, Mitchell \& Hooper 1999). They tracked learners from the start of their French learning, at age 11 or 12, for two years. The first thing that's striking about their findings is that these young people were still able to do some of what Nora was doing: memorising formulaic phrases and then using them beyond their normal scope. Indeed, the teachers ENCOURAGED the learning of chunks, such as je m'appelle... 'my name is ...' and où habites-tu.? 'where do you live?'. The students apparently did not begin with much idea of how those strings were made up, but they knew what they meant and what to do with them.

There is a lot of sense in beginning language teaching with some useful formulaic expressions like that. They give the learner a chance to have simple conversations and feel somewhat competent in the early stages. But of course, you can't spend your entire life saying 'My name is Alison' and 'Where do you live?', and so in due course they encountered the same problem that Nora did: what do you do when you want to say something that is RATHER like what you have a formula for, but not exactly the same? Well, they did the same as Nora: they used what they had as a sort of blunt instrument to try and convey the new meaning. One of them, trying to say 'Richard loves table tennis' said: Richard est j'adore le pingpong Richard is I love table-tennis', using the previously memorised wordstring j'adore 'I love'. Another, trying to say 'what's the girl's name?' said comment t'appelles-tu la fille? 'What's your name the girl', using the memorised string comment t'appelles-tu 'what's your name?' (Myles et al. 1999: 51).

\footnotetext{
${ }^{7}$ The Southampton study is valuable on account of the quality of information it offers about the approach to learning taken by the students, and the attitudes towards their learning taken by the teachers. Their problems with grammar teaching seem not to apply to all learner situations. For example, Richard Johnstone found that Croatian children learning French as a foreign language benefited from relating metalinguistic knowledge about their L1 to the foreign language, so that they had a command of explanations about form far in excess of the Southampton learners (personal communication). The Croatian learners appear to have been undergoing the same kind of transition to intellectual learning as Katie with her Japanese (see later).
} 
As I've said, this is the kind of thing that Nora did too. But of course Nora was in a much richer learning environment, with a lot more input coming at her, so she was soon able to figure out better ways of saying things. One of the ways that she might have done this is by noticing how people said things that were partly identical to what she had learned, and partly not, so that she began to notice the boundaries WITHIN what she'd memorised: then she could swap parts in and out, and create a broader range of meanings. This, at least, is how Ann Peters (1983) proposes that children go about figuring out how to say new things in their FIRST language.

Perhaps that's what the French learners in the Southampton study were supposed to do too, but they seemed to find it difficult to progress to that stage. The outcomes weren't impressive: after two years of tuition, these pupils had very little ability to express themselves in French. How can this be explained? Of course, they had a much smaller amount of quality input and fewer opportunities to use the language in genuine communication than Nora did. On the other hand, classroom learners can make use of many aids that a kindergarten child in immersion does not have: books, worksheets, explanations, and so on. The written medium provides an extra source of support for the learner, and also assists the teacher in maintaining structure to the input: a well-constructed course-book takes the learners step-bystep through the language, ideally maximising comprehension by locating new information within previously learned material (Dulay, Burt \& Krashen 1982). Of course, such forms of input tend to externalise the language into an object of study, making its role as a medium of communication less obvious. But structured written input is just capitalising on the intellectual awareness that Wong Fillmore's older children seemed to be developing naturally anyway. It would therefore seem reasonable to replace Nora's implicit learning of, say, some grammatical structure, with a direct explanation of it, along with examples and plenty of practice.

Although the outcomes might not generally be quite as good (Singleton 2005), the intellectual approach can in fact be faster to produce results (Muñoz 2006b: 29f.), because explicit learning offers short cuts relative to implicit learning (De Keyser 2005: sect. 5; Muñoz 2006b: 33). Edelenbos, Johnstone \& Kubanek (2006: 147) indeed conclude that direct attention to how language works is a means of developing language aptitude.

It's interesting to discover, therefore, that the teachers in the Southampton study didn't offer much grammar tuition. They didn't think that Year 8 pupils (12-13 years) were sufficiently 'mature' to cope with grammar (Mitchell \& Martin 1997: 12). 'Mature' is an interesting word here. Although we normally worry about whether a learner has passed the critical period for learning languages, here, the teachers were viewing their students as too YOUNG to learn the language, not too OLD. This must reflect the teachers' perceptions and expectations - not unreasonable ones - about how a language is learned in a classroom situation: not in the same way as a child learns, but rather in what we might term the 'adult', intellectual way.

The intellectual approach to learning means that the teacher needs to explain aspects of the grammar, and the students need to understand them. This is explicit knowledge, not the kind of implicit knowledge that Nora acquired through trial and error. Yet the teachers had found over the years that 11 to 14 year olds just couldn't cope with that. They found grammar 'difficult', 'confusing' and 'irrelevant'. One teacher said: 'I've started to introduce the perfect tense, but I know that for about half the children it probably doesn't mean much ... [However] I have got a few in the class who will eventually understand tenses' 
(Mitchell \& Martin 1997: 21). The teachers didn't expect most of the pupils to grasp even basic concepts such as that French has two noun genders (Mitchell \& Martin 1997: 14f.). Meanwhile, they talked of the high ability pupils having 'an obsession with what each part of [a] phrase might mean' (p.15). That's another interesting word, 'obsession'. These were the students who were trying to learn the adult way, by separating out the patterns. So it seems that the teachers had a problem: MIXED classes. Some could learn the adult way and some couldn't.

Perhaps, then, the problem is that 11 or 12 is exactly the WRONG age to start teaching a foreign language: some of the class will already have made the transition into an adult perception of learning, while others haven't. You should begin either later, when they've all made the transition, or earlier before they get there (Wray 2002: 197).

But there's something else hidden in here too. The teachers weren't saying 'give it a couple of years and they'll all understand'. One said 'of course some of them [Year 8] have reached their linguistic ceiling' (Mitchell \& Martin 1997: 22). In other words, the teachers seemed to believe that some of the children would NEVER be able to grasp how to learn another language.

It is important to consider the possible significance of their belief. The teachers seemed to perceive the transition from child-like learning to adult learning as a transition from something that ALL children can do - acquire a language the 'Nora' way - into something that only a FEW can do - learn a language the intellectual way. If so, there are some wide-reaching implications, which I'll come back to in a minute.

But for now let's follow a different line. If you want to introduce all children to a foreign language, and do so successfully, surely it does make sense to do what Dearing has recommended: start them at the age of 8 , when none of the children have got to that transition point. They can all learn the 'Nora' way. . UNLESS, of course, it is actually learning a new language in a classroom setting that constitutes the catalyst for the transition. Let's switch back to Katie for a minute and see what happened to her in the course of the next year and a half in her Japanese classes.

\section{Learning to learn a language}

A few weeks ago, in anticipation of this lecture, I e-mailed Katie with a few questions. First I asked: 'What can you remember about what it felt like when you started learning Japanese?' She replied: 'For me it was kind of boring and annoying because everyone was speaking a language I had no idea how to speak and everyone was so ahead of me.' I asked: 'How do you feel about learning Japanese now?' She said: 'I love Japanese now because I have caught up with my class and I know what's going on.' 'Which class activities do you enjoy?' 'I really like listening to recordings and watching a film because it really makes me think.' And recall that when she first joined the class, it was films that she found most difficult to cope with. Finally, I asked: 'What are the hardest things about learning Japanese?' She said: 'Learning all the hiragana characters was one of the hardest things for me but once I cracked them it was easy and more fun.'

We can see that, even between the age of $8 \frac{1}{2}$ and 10 , Katie's perception of language learning has radically changed. She now sees learning Japanese as an intellectual exercise, 
made up of manageable components. She has mastered some of these components and as a result she feels capable. Katie is a bright and motivated child and her mother tells me she's now one of the best at Japanese in the class. But for children who don't have her application, her ability, or her confidence, it could be a different story. Remember that when she first joined the class she felt excluded, which made the lessons 'boring and annoying'. She has overcome that problem, but there will be other children who are now feeling exactly like that, and who will become disillusioned with the whole idea of learning Japanese. In other words, we are seeing how a class of children, even of primary school age, could fragment along lines of intellectual ability and determination - into those that can cope and those that can't. Rather than the equality that children are supposed to bring to language learning, we may be seeing the classic symptoms of adult learning, including differences in motivation and aptitude, but superimposed onto individuals not yet fully trained in how to engage intellectually with inherently complex information.

All of this raises two questions that I want to briefly address. First of all, does it matter? What are the consequences of learning a language the 'intellectual' way? Secondly, is there any way to get around this transition, and helping older learners to learn like successful younger ones?

\section{What are the consequences of learning a language the 'intellectual' way?}

Although there are a great many people who successfully master another language in adulthood to the point of being highly proficient and even native-like, it remains, I think, incontrovertible that for most people the intellectual approach to language learning does NOT result in a native-like outcome. The reasons are certainly manifold, but here I want to mention just one possible cause, using an illustration from a research project that has been developed at Cardiff. The project is based around a task involving cartoons, called, rather unimaginatively, The Cardiff Cartoon Task. There are 15 cartoons like the one in Figure 1. The question we asked various groups of native and non-native speakers was this: What do you think the native speakers in our study most commonly say should go in the gap? ${ }^{8}$

I want to look at one particular response that we have had from a lot of non-native speakers when shown this prompt. It is Lady first. What's interesting is how logical it is. The first thing to realise is that you're unlikely to produce that answer at all unless you have encountered Ladies first. But these learners clearly have not simply picked up the expression and reused it as it is. They seem to have reasoned that ladies is plural, but as there's only one woman here, the expression needs to be singular. As a result, they have come up with something that is comprehensible, grammatical and sensible - it's just not what we say.

In truth, the best thing to do with Ladies first is what Nora would have done with it: hear it, remember it, use it, without trying to figure out why it has the form it has, unless and until you see specific evidence from other input that indicates how it can be changed. This input-driven, conservative approach to language learning is what I have termed NEEDS ONLY ANALYSIS (Wray 2002: 130-132), and it seems difficult for adult learners to adopt: or rather,

\footnotetext{
${ }^{8}$ The framing of the question maximises the production of perceived archetypes rather than personal preferences.
} 


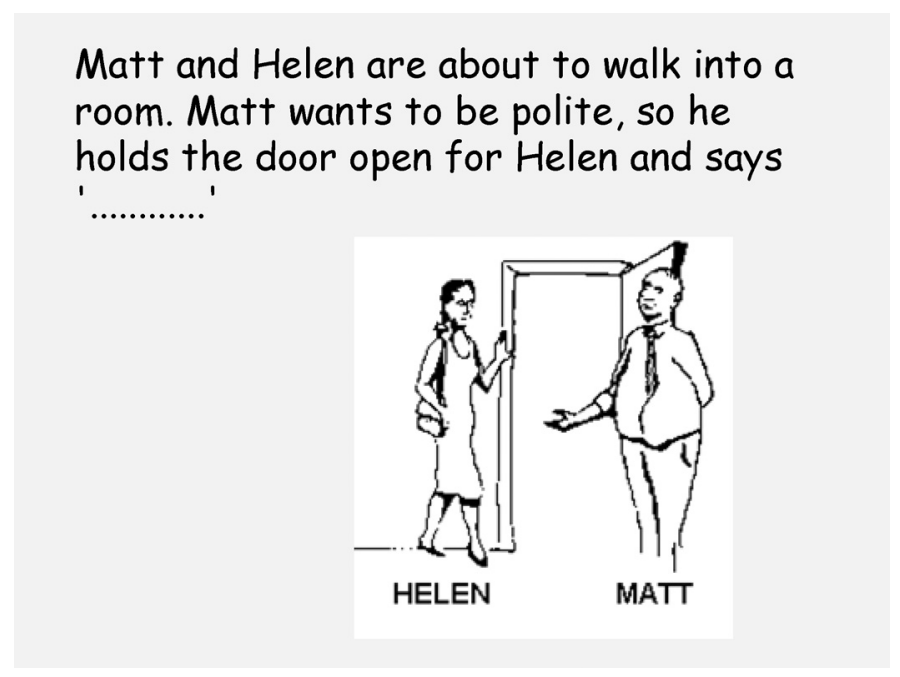

Figure 1 Example prompt in The Cardiff Cartoon Task.

I think they DO operate it, but their needs are different, and that means that they analyse the language more, in order to meet those needs.

The adult approach seems to be one of mastering the language by trying to understand how all the parts work. And you do that by trying to break the material down into small components, little building bricks, and then looking for rules to recombine them: a sort of LEGO approach to language learning. The problem arises because sometimes when you use words and rules to create a nice logical, grammatical sentence, you don't end up with the native-like version, because languages just aren't that logical. In other words, you will generate not only many fully acceptable, idiomatic sentences but also a great many that OUGHT to be okay, but just aren't. That means that, to be idiomatic, you need to know the SUBSET of what is logically POSSIBLE in language that is also native-like.

Now, this suggests that the answer to more effective language learning by adults might be to learn in larger chunks. If their approach to learning is determined by their needs, then can their needs be manipulated to the point where they can learn more like a child? We've come, then, to my second question: Can adults get round this transition, and learn more like children? This is one of the issues that I have been exploring in my research, and I'd like to tell you very briefly about two investigations that I've done.

\section{Extreme learning}

In some of my recent research (Wray 2004; Fitzpatrick \& Wray 2006; Wray \& Fitzpatrick 2008), I have been using extreme situations to see what happens when you make it as easy and desirable as possible for adult learners to memorise and use pre-formulated native-like material. The reason for this research was to find out to what extent adults actually CAN learn 
in larger chunks, like young children. It could be that they can, but just tend not to because of circumstances in their learning experience, such as the way material is presented to them. Alternatively it could be that there are some more or less intractable features of being an adult learner that will consistently prevent the exploitation of formulaic material.

This kind of investigation is not an easy thing to engineer. You have to somehow remove as many as possible of the various elements of the normal adult language learner's experience that might be preventing them from picking up and using native-like strings of words. Although it might seem rather attractive to learn to say exactly what native speakers say, there can be legitimate reasons for learners being cautious about doing so. For a start, they might not actually WANT to sound too much like a native speaker, in case they are mistaken for one. Native speakers talking to each other can make assumptions about shared linguistic and cultural knowledge that they would not assume when talking to an 'outsider' (Wray \& Grace 2007), and a learner may wish to avoid too much being taken for granted. Furthermore, many adult learners resist the sense of losing their own native identity. An additional reason why learners might not normally prioritise learning multiword strings is based on pragmatism: they reason that there is little point in memorising a small number of specific native-like expressions when it's unlikely that any real situation will call for exactly what has been learned. Rather they would prefer to learn how to construct their own sentences, so that they are equipped for whatever situation might arise.

The way we went about shifting these priorities was, first of all, to recruit individuals to the study who did see a usefulness in learning to sound more native-like - normally because, despite being fairly proficient, they were struggling to cope with certain types of interaction in their daily life. Secondly, we used situations in which there was a stronger than normal likelihood of the memorised material being useable in the near future.

In one study, a beginner learner of Welsh was challenged on a television programme to present a complete cookery demonstration in Welsh to a live audience, at only four days' notice. The television programme was Welsh in a Week, shown on the Welsh station S4C, and the terrified participant was Margaret Owen (Wray 2004). In each half-hour episode of Welsh in a Week, someone who doesn't know any Welsh but who lives or works in an environment where they could use Welsh if they knew it, is challenged to learn in four days enough Welsh to carry out a particular activity. I went on location with the TV crew when they filmed Margaret learning enough Welsh to demonstrate the preparation of pork and mushroom casserole, and lemon pudding. Quite clearly, in such a setup there isn't time to teach lots of vocabulary on its own, or much in the way of grammatical rules. So the learner is given complete phrases and sentences to memorise. As Margaret was a beginner, I was able to track what she knew and how well she memorised it, using my field notes, the tutor's materials, interviews, and all the footage recorded over the five days. It was a very interesting situation. Margaret was being expected to do something well beyond her true capabilities. Although it was a 'performance', the communication nevertheless was genuine: she was explaining something real - and demonstrating it - to people who really wanted to know. On the other hand, she was protected from one of the most challenging unknowns in language use: having other people speak back to you. She had the floor, uninterrupted.

Margaret was highly motivated to learn her Welsh, for she needed it. She had no knowledge reserves to rescue herself if things went wrong - she could not improvise in Welsh. Not 
surprisingly, she practised her lines till she knew them off by heart. All she had to do was reproduce them. And did she? - No. She changed things, even though it wasn't in her interests to do so. She altered things that didn't need to be altered, leading to non-native-like speech. How, you might ask, could she do that when she didn't know any Welsh? What was she using as the basis for the changes? The analysis that I did of what she said (Wray 2004) revealed that she made changes in the locations where, in the course of the input over those four days, she had been shown that changes could be made. In essence, wherever the tutor had indicated 'here is a place where you can do either this or that' she seemed to have mentally marked it as needing an intervention, a decision. And that invited her, apparently, to introduce errors. For instance, a feature of the Welsh language is the front-mutation of words: Caerdydd 'Cardiff', o Gaerdydd 'from Cardiff', yng Nghaerdydd 'in Cardiff'. Where Margaret had had drawn to her attention that a particular word was in a mutated form, she tended to change it to the unmutated form. But where she had not realised that a form was mutated, it remained unchanged.

The other study was an experiment using six intermediate learners of English. They were Chinese and Japanese postgraduate students, with English that was good enough to make themselves understood, but not anywhere near native-like. What we did was get them to think about a situation they expected to be in very soon, where they could do with having some native-like things to say. They came up with situations like phoning a friend to arrange dinner and a trip to the cinema, coaching someone in badminton, and attending a tutorial. One participant even wanted to take her pet hamsters to the vet to find out why they hadn't mated. My colleague, Tess Fitzpatrick, worked one-to-one with each person. The participant told Tess what she'd like to say as this anticipated situation unfolded, and Tess gave her a native-like way of saying it. Twelve or so sentences were prepared per conversation. Then the participant went away and memorised the material, coming back a few days later to practise it with Tess. Finally, she was sent off with a digital recorder, to have the real conversation.

As with Margaret, it really was in the interests of our experimental participants to just use the material that they had memorised: they wanted to sound more native-like - that's why they joined the project - and they knew that they knew the material. So they just had to reproduce it. But they didn't, not entirely. They could do it off line, in rehearsal, but put them into the real situation, and it started to come apart. They changed things, they added errors, they just couldn't leave it alone. In fact, it looks as if this Lego approach was pretty well impossible for them to overcome. They really struggled to use prefabricated material in real interaction, and seemed intent on breaking it down and then trying, not always very successfully, to reconstruct it. Why was that? What was it about being in a real interactive situation that made them rely more on their incomplete and inaccurate knowledge of the words and rules, than on the native-like sentences they had memorised? I think it comes back to the question of how you perceive the language.

The young child thrown into the L2 situation sees a language as something you KNOw. And that means that as soon as you have even just a few words under your command, you start to count as someone who KNOws it. You step inside the circle of users, and get on with using it. You're a bit of a bull in a china shop, but you're in there, doing it. And that is a great way to learn. Perhaps one reason that children are good at learning that way is because they are so accustomed to being relative newcomers, with a lot to learn, so it doesn't faze them. 
Language learning for them is just like playing football in the garden - you don't have to be good at it yet, but even when you are not good at it, you are still an equal participant in the game.

In contrast, adults see a language as something you LEARN. They feel that they don't know it yet, though one day they might. Viewed that way, they are always in deficit, waiting to learn enough to be able to say they are STARTING to know it. That puts them on the outside, trying to figure out how to get in. It's as if they're watching everyone else playing football, wondering when, if ever, they will be good enough to join in. So, not surprisingly, they are watching all the moves, trying to figure out the rules, rather than getting in there and learning by kicking the ball about. This creates a habit in relation to engaging with the language that is difficult to break, even when one has developed reasonable proficiency. Those who make it all the way to native-like fluency evidently do get to play football, so to speak, but as I said earlier, they are in the minority; and it's not at all clear that, in terms of processing, they are actually playing quite the same game, even though they make all the right moves.

\section{Conclusion}

Where does this leave us? In the context of the new languages policy recommended by Dearing, the question is: Is 8 years old a good age to start learning a language? Certainly by age 11 it looks as if we're between a rock and hard place, with the class divided into those that have figured out adult-style learning, and those that have not. Will it help, though, to push the starting age down to 8? Is that a way to capture more of that natural ability and confidence, before it finally disappears? Maybe, but only if you can find a way not to simply make the transition to adult-style learning occur earlier. Because if it does, at that younger age even more children will struggle to cope with the intellectual challenge of adult-style language learning and will be put off. As Edelenbos et al. (2006: 147) observe, 'An early start by itself ... guarantees nothing; it needs to be accompanied minimally by good teaching, by a supportive environment and by continuity from one year to the next'. Ensuring teachers are confident and competent to deal with the specific needs of younger learners is obviously paramount (e.g. Nikolov \& Djigunovic 2006: 251; Woodgate-Jones 2008). ${ }^{9}$

Evaluating the 1960s project, Burstall et al. (1974: 243) commented: 'It is cruelly naïve to cling to the belief that by introducing French at an early age, all children will begin their study of the language from an equal standpoint'. Burstall et al. go on to say that, even at age 8 , differences in confidence, facility with the L1, and experiences of success and failure will separate children out. They found that by the end of the first year of tuition, some children had developed a sense of failure about language learning that could only impede future learning. Katie's experience with Japanese indicates just how

\footnotetext{
${ }^{9}$ Indeed, a feasibility study undertaken in 2000 (Qualifications and Curriculum Authority 2001) warns against introducing a national entitlement to foreign language tuition at Key Stage 2 without first ensuring that the resources and infrastructure are adequate to support it, including appropriate and effective training. Details of what that training should entail are outlined in Martin (2000) and evaluations of the current provision in UK teacher training institutions are reported in Woodgate-Jones (2008). The QCA report also flags the requirement for convincing evidence that material benefits ensue from starting tuition at the younger age.
} 
disconcerting it can be to feel excluded from a group that knows more than you, and just how much determination and intellectual application is needed to break through that barrier.

It seems very possible that, in a literate culture, with resource limitations and a target-driven approach to education like that in the UK, there really is no way to prevent foreign language classes, even in the primary years, transforming from a well-meaning initial communicative approach into something more analytical, other than in true immersion learning. If so, and if we accept that not everyone has the intellectual talent to learn a language the adult way, perhaps language learning should be a much LATER activity, reserved just for the elite who show interest and aptitude by their early- to mid-teens.

That would be one way to go. Another, though, is to hold onto the belief that languages ARE for all, and strive to find a way to make that work. We might aim to ensure that young children get good quality, relevant foreign language input, from native speakers if possible, and lots of chances to use the language (Martin 2000; Teacher Training Agency 2004). But we can't forget that the activity is classroom-bound and very restricted in time. 'In a typical school syllabus. . . exposure is very scarce and probably insufficient for children to be able to make use of implicit learning mechanisms' (Muñoz 2006b: 33). Children learning implicitly may learn BETTER than adults, but it takes LONGER (De Keyser 2005: sect. 5). With so little exposure on offer, it's not surprising that teachers are tempted to introduce shortcuts in learning, explaining to the children how this or that pattern works, so that fewer examples are needed to make it stick. But the Southampton study showed that that sort of explanation is not well received, and children soon perceive language learning to be too difficult for them. So what else can we do?

Nora learned formulaically, and so did the children in the Southampton study, so perhaps input based around formulaic learning can be used in the 8 year olds' classroom. The advantage of learning language in larger chunks is that the irregularities are hidden inside, and the forms can become comfortable to say and use without agonising over choices of word and word-ending. Multiword input prevents the learner being confused by the irregularities that all languages seem to have. Of course, learning complete wordstrings is very restrictive in terms of what you can actually say, and that's why a formulaic approach to teaching could not really be a REPLACEMENT for the more analytic approach. But it could postpone it, and then supplement it.

Effective formulaic teaching needs to be carried through by teachers who are not, at every turn, anxious to move into explanations. It needs to be rooted in the energetic promotion of activities that make the memorised strings useful and effective (e.g. Gatbonton \& Segalowitz 1988), even if the formula ends up getting used beyond its appropriate scope. My sense is that the teacher must resist drawing out patterns for the learner, though it would be reasonable to confirm what the learner works out for herself and asks about.

The sort of formulaic input I'm talking about here is very different from that which often features in materials for younger children: songs and rhymes, lists like the numbers and days of the week, and so on. Nora's formulaic material helped her communicate. She picked up other people's turns of phrase, and used them to shoehorn her way into interaction. Nursery rhymes are no use for interaction. They may help with pronunciation fluency, but not much more. Their vocabulary is at times bizarre (tuffet, Margery Daw) and collocations 
misleading: how do you trot home as fast as you can caper? Meanwhile, although lists of the days of the week and so on are certainly helpful in one way, they are mnemonics and can't be used to actually SAY much. That kind of formulaic material is of limited value and it grossly underestimates what children might be able to do with language if they are given the chance.

The materials currently in preparation in response to the Dearing report do indicate a recognition that introducing communicatively useful multiword strings has value (Qualifications and Curriculum Authority 2007), but much will depend on whether teachers are trained to use this material effectively. We might take a leaf from China's book here formulaic learning is well tried and tested there, and can have extraordinarily good results (e.g. Ding 2007).

To sum up, I suspect we can never stop the transition occurring altogether, so that in the end language learning gets mapped onto other kinds of learning that are more reductionist and rule-bound than languages really are. But if we can figure out how to help children not make that transition to adult learning so early on - not until they already have a clear belief that they KNOW the language, just not perfectly yet - then we may find that they come out with a very different attitude towards learning languages. ${ }^{10}$

\section{Acknowledgements}

I should like to thank four Language Teaching reviewers for very helpful comments on this written version of the talk.

\section{References}

Action Group for Languages (2000). Citizens of a multilingual world. Report to the Scottish Executive. $<$ http://www.scotland.gov.uk/library3/education/mwki-00.asp > accessed 25/11/07.

Burstall, C., M. Jamieson, S. Cohen \& M. Hargreaves (1974). Primary French in the balance. Slough: National Foundation for Educational Research.

Cenoz, J. (2002). Age differences in foreign language learning. ITL Review of Applied Linguistics 135/ 136, $125-142$.

CILTCymru (2006). Key Stage 2 primary project. <www.ciltcymru.org.uk/english/primary/Homepage/ phase 1_info.htm > accessed 28/10/07.

Commission of the European Communities (2003). Promoting language learning and linguistic diversity: An action plan 2004 - 2006. < http://ec.europa.eu/education/doc/official/keydoc/actlang/ act_lang_en.pdf $>$ accessed 28/10/07.

De Keyser, R. (2000). The robustness of critical period effects in second language acquisition. Studies in Second Language Acquisition 22.4, 499-533.

\footnotetext{
${ }^{10}$ Perhaps seeing oneself as a KNOWER rather than a LEARNER contributes to completing one's L2 learning successfully even after one has made the transition to adult-style learning. The advantages of the adult's intellectual approach, combined with the belief that one is already a bona fide user of the language, could maximise fast and effective learning. If so, probably a knower would need to be located in a context where it meant something to know the language (i.e. where there were native speakers to interact with, or, as with English in so many parts of the world, there was a desirable cultural and material outcome to learning). The mastery of L2 phonology - known to be easier for younger learners - might play a part too, since native-like pronunciation will encourage others to treat the learner as an insider.
}

\section{CAMBRIDGE JDURNALS}


De Keyser, R. (2005). Implicit and explicit learning. In C. J. Doughty \& M. H. Long (eds.), The handbook of second language acquisition, part IV, chapter 11. Oxford: Blackwell. Blackwell Reference Online <http://www.blackwellreference.com/subscriber/uid=60/book?id=g9781405132817 9781405132817> accessed 28/10/07.

DES (Department of Education and Skills) (2007). Languages review. < http://www.teachernet. gov.uk/_doc/11124/LanguageReview.pdf> accessed 28/10/07.

Ding, Y. (2007). Text memorization and imitation: The practices of successful Chinese learners of English. System 35, 271-280.

Dulay, H., M. Burt \& S. Krashen (1982). Language two. New York: Oxford University Press.

Edelenbos, P., R. Johnstone \& A. Kubanek (2006). The main pedagogical principles underlying the teaching of languages to very young learners. Report to the European Commission, EAC 89/04, Lot 1 study. <http://ec. europa.eu/education/policies/lang/doc/young_en.pdf> accessed 25/11/07.

Fitzpatrick, T. \& A. Wray (2006). Breaking up is not so hard to do: Individual differences in L2 memorisation. Canadian Modern Language Review 63.1, 35-57.

Gatbonton, E. \& N. Segalowitz (1988). Creative automatization: Principles for promoting fluency within a communicative framework. TESOL Quarterly 22.3, 473-92.

INRA (2001). Europeans and languages. Report for the Education and Culture DirectorateGeneral. Eurobarometer 54 Special Survey on Languages. <http://ec.europa.eu/public_opinion/ archives/ebs/ebs_147_en.pdf> accessed 28/10/07.

Itoh, H. \& E. Hatch (1978). Second language acquisition: A case study. In E. M. Hatch (ed.), Second language acquisition: A book of readings. Rowley, MA: Newbury House, 76-88.

Krashen, S. (1985). The input hypothesis. London \& New York: Longman.

Lenneberg, E. (1967). Biological foundations of language. New York: Wiley \& Sons.

Martin, C. (2000). An analysis of national and international research on the provision of modern foreign languages in primary schools. Report for the Qualifications and Curriculum Authority. <http://www. qca.org.uk/libraryAssets/media/3809_cmartin_rpt_mfl_primaryschools.pdf> accessed 25/11/07.

Mitchell, R. \& C. Martin (1997). Rote learning, creativity and 'understanding' in classroom foreign language teaching. Language Teaching Research 1.1, 1-27.

Muñoz, C. (2006a). Introduction. In Muñoz (ed.), vii-xi.

Muñoz, C. (2006b). The effects of age on foreign language learning: The BAF project. In Muñoz (ed.), $1-40$.

Muñoz G. (ed.) (2006c). Age and the rate of foreign language learning. Glevedon: Multilingual Matters.

Myles, F., J. Hooper \& R. Mitchell (1998). Rote or rule? Exploring the role of formulaic language in classroom foreign language learning. Language Learning 48.3, 323-363.

Myles, F., R. Mitchell \& J. Hooper (1999). Interrogative chunks in French L2: A basis for creative construction? Studies in Second Language Acquisition 21.1, 49-80.

Nikolov, M. \& J. M. Djigunovic (2006). Recent research on age, second language acquisition, and early foreign language learning. Annual Review of Applied Linguistics 26, 234-260.

Penfield, W. \& L. Roberts (1959). Speech and brain mechanisms. Princeton, NJ: Princeton University Press.

Peters, A. M. (1983). Units of language acquisition. Cambridge: Cambridge University Press.

Qualifications and Curriculum Authority (2001). QCA project to study the feasibility of introducing the teaching of a modern foreign language into the statutory curriculum at Key Stage 2. < http://www.qca. org.uk/libraryAssets/media/3807_mfl_feas_ks2.pdf> accessed 25/11/07.

Qualifications and Curriculum Authority (2007). New Key Stage 2 scheme of work for languages. $<\mathrm{http}: / / \mathrm{www}$. qca.org.uk/qca_11752.aspx > accessed 01/11/07.

Robinson, P. (ed.) (2002). Individual differences and instructed language learning. Amsterdam: John Benjamins.

Singleton, D. (2001). Age and second language acquisition. Annual Review of Applied Linguistics 21, 77 89.

Singleton, D. (2005). The Critical Period Hypothesis: A coat of many colours. IRAL 43, 269-285.

Teacher Training Agency (2004). A systematic review of the characteristics of effective foreign language teaching to pupils between the ages 7 and 11. Report by the Modern Languages Review Group. London: EPPICentre, Institute of Education. <http://eppi.ioe.ac.uk/cms/Default.aspx?tabid=303> accessed $25 / 11 / 07$.

Wong Fillmore, L. (1976). The second time around: Cognitive and social strategies in second language acquisition. Ph.D. dissertation, Stanford University.

Wong Fillmore, L. (1979). Individual differences in second language acquisition. In C. J. Fillmore, D. Kempler, \& S-Y. W. Wang (eds.), Individual differences in language ability and language behavior. New York: Academic Press, 203-228. 
Woodgate-Jones, A. (2008). Training confident primary modern foreign language teachers in England: An investigation into pre-service teachers' perceptions of their subject knowledge. Teaching and Teacher Education 24.1, 1-13.

Wray, A. (2002). Formulaic language and the lexicon. Cambridge: Cambridge University Press.

Wray, A. (2004). 'Here's one I prepared earlier': Formulaic language learning on television. In N. Schmitt (ed.), Formulaic sequences: Acquisition, processing and use. Amsterdam: John Benjamins, 249-268.

Wray, A. \& T. Fitzpatrick (2008). Why can't you just leave it alone? Deviations from memorized language as a gauge of native-like competence. In F. Meunier \& S. Granger (eds.), Phraseology in language learning and teaching. Amsterdam: John Benjamins.

Wray, A. \& G. W. Grace (2007). The consequences of talking to strangers: Sociocultural influences on the lexical unit. Lingua 117.3, 543-578.

AlisOn WraY is a Research Professor in Language and Communication at Cardiff University, UK, and Director of Research for the Cardiff School of English, Communication and Philosophy. Her publications cover several research interests, most notably formulaic language and the evolutionary origins of language. Her book Formulaic language and the lexicon (Cambridge University Press, 2002) won the 2003 book prize of the British Association for Applied Linguistics. 